\title{
Regulatory $T$ cell and cytokine changes in children undergoing 3 days rush venom immunotherapy
}

\author{
Tipyapa Rattanamanee, ${ }^{1}$ Putthapoom Lumjiaktase, ${ }^{2}$ Nanthisa Kemawichanura, ${ }^{2}$ Potjanee Kiewgnam, ${ }^{1}$ \\ Wanlapa Jotikasthira, ${ }^{1}$ Wiparat Manuyakorn ${ }^{1}$
}

\begin{abstract}
Background: Rush venom immunotherapy (VIT) is the recommended treatment for patients with Hymenoptera anaphylaxis. Specific data regarding regulatory $\mathrm{T}$ cell and cytokine changes in children receiving rush VIT are sparse.

Objective: To study the changing of $\mathrm{CD} 4^{+} \mathrm{CD} 25^{+} \mathrm{FOXP}^{+}$regulatory $\mathrm{T}$ cells $\left(\mathrm{T}_{\text {reg }}\right)$ and serum cytokines in children undergoing 3 days rush VIT.

Methods: Children younger than 15 years with systemic reaction to Hymenoptera who had evidence of IgE sensitization to Hymenoptera were enrolled for 3 days rush VIT. Peripheral blood CD $4^{+} \mathrm{CD} 25^{+} \mathrm{FOXP} 3^{+} \mathrm{T}_{\text {reg }}$ and serum IL-4, IL5, IL-13, IFN- $\gamma$, and IL-10 were measured at baseline before rush VIT, achieving maintenance dose, 6 months, and 12 months after reaching maintenance dose. Specific IgE to Hymenoptera was measured at baseline and 12 months after VIT.

Results: A total of 15 children (11 boys and 4 girls) aged 6-15 years (mean age, 10 years) were enrolled. Four children were allergic to bee and 11 children were allergic to Vespid. The levels of $\mathrm{CD} 4^{+} \mathrm{CD} 25^{+} \mathrm{FOXP} 3^{+} \mathrm{T}_{\text {reg }}$ were significantly increased at 6 months after maintenance dose compared with baseline (6.58\% VS 4.01\%, $p=0.001)$. Serum IL-13, IFN- $\gamma$, and IL-10 levels did not change significantly from baseline. However, there was a significant reduction of IL-4 in the serum at 12 months after MN when compared to the baseline levels. The systemic reaction requiring epinephrine intramuscular injection occurred only in 1 case who was on Vespid venoms rush VIT.
\end{abstract}

Conclusions: Three days rush VIT provide acceptable systemic reaction and able to increase the number of $\mathrm{CD} 4^{+} \mathrm{CD} 25^{+-}$ $\mathrm{FOXP}^{+} \mathrm{T}_{\text {reg }}$ in children.

Key words: Subcutaneous immunotherapy, Hymenoptera, Anaphylaxis, regulatory T cells, cytokines, children

From:

Department of Pediatrics, Faculty of Medicine Ramathibodi Hospital, Mahidol University, Bangkok, Thailand

2 Department of Pathology, Faculty of Medicine Ramathibodi Hospital, Mahidol University, Bangkok, Thailand

\section{Introduction}

Allergic reactions to Hymenoptera sting range from mild to severe systemic reactions. Venom immunotherapy (VIT) is currently the recommended treatment for severe reactions. VIT is the only treatment that long-term tolerance can be achieved. ${ }^{1}$ VIT has proven to be effective for between 80 and $95 \%$ of patients with Bee venom and Vespid venoms allergy. ${ }^{2}$ Mechanism of immune-tolerance from VIT was proposed to involve an increase in the number of regulatory $\mathrm{T}$ cells, ${ }^{3}$ increases of interferon (IFN) $-\gamma$ and IL-10, ${ }^{4}$ and decreases of

\author{
Corresponding author: \\ Wiparat Manuyakorn \\ Division of Allergy and Immunology, Department of Pediatrics, \\ Faculty of Medicine Ramathibodi Hospital, Mahidol University \\ Rama 6 Rd, Ratchathewi, Bangkok 10400, Thailand \\ E-mail: mwiparat@hotmail.com
}

IL-4 and IL-5. ${ }^{5}$ The dose of VIT need to achieve the maintenance $(\mathrm{MN})$ dose to get the immune-tolerance. Conventional VIT requires 3-4 months to reach $\mathrm{MN}$ dose, but accelerated protocols such as rush VIT has shortened the build-up phase into a few days. Rush VIT also provides instant effectiveness with comparable reactions to conventional VIT. However, there are some differences in the protocol of rush VIT especially in children and there is scarce evidence on the dynamic change of regulatory $\mathrm{T}$ cells and cytokines after 
rush VIT in children. The current study was aimed to evaluate the changes of $\mathrm{CD}^{+} \mathrm{CD} 25^{+} \mathrm{FOXP}^{+}$regulatory $\mathrm{T}$ cells in children during the 12 months after 3 days rush VIT. In addition, serum cytokines including IL-4, IL-13, IL-10, and IFN- $\gamma$ were evaluated.

\section{Methods \\ Patients}

This prospective study included children aged 6-15 years with histories of severe allergic reactions to Hymenoptera sting and having evidence of IgE sensitization to Hymenoptera from February 2017 to July 2019 at Department of Pediatrics, Faculty of Medicine Ramathibodi Hospital. All participants were hospitalized for 3 days rush VIT using the venom of bee, mix vespid (yellow jacket, yellow hornet, and white face hornet) (ALK Abello, Hørsholm, Denmark). The detail of rush VIT administrations was shown in Table 1. Premedication with oral antihistamine was administered in the morning at least 30 minutes before the first dose of VIT. Systemic reactions from VIT were graded according to The World Allergy Organization Subcutaneous Immunotherapy Systemic Reaction Grading System. ${ }^{6}$ Specific IgE to Hymenoptera using ImmunoCap (Phadia, Biomed diagnostics, Bangkok, Thailand) was evaluated before starting of VIT and after 12 months of MN dose. Peripheral mononuclear cells (PBMCs) and serum were collected at before, achieving MN dose, 6 months after $\mathrm{MN}$ dose, and 12 months after MN dose. All participating subjects or parents were informed of the contents and the aims of the study and they gave their written consent. The study was reviewed and approved by the human rights and Ethics Committee of Faculty of Medicine Ramathibodi Hospital, Mahidol University (ID 01-60-08).

\section{Materials and Reagents FOXP3 $^{+} T_{\text {reg }}$ identification}

In brief, fresh heparinized whole blood samples $(6 \mathrm{~mL})$ were collected from patients at each time-point. Peripheral blood mononuclear cells (PBMCs) were isolated using SepMate $^{\mathrm{TM}}-15$ tubes (STEMCELL Technologies) and Lymphoprep (Alere Technologies AS, Oslo, Norway), centrifuged with 1200 $\mathrm{g}$ for $20 \mathrm{~min}$ in room temperature. PBMC layer at the interface was collected and twice washed $3500 \mathrm{rpm}$ by phosphate buffer saline (PBS) for 5 min. PBMCs were resuspended with RPMI medium-1640 (Glico technology), which used to study the number of FoxP3 $\mathrm{T}_{\text {reg }}$ by flow cytometry. $1 \times 10^{6}$ cells of PBMCs were incubated with mouse anti-human CD4 FITC and anti-human CD25 FITC (BD Bioscience) for extracellular staining and anti-human Foxp3 (eFluor 660, eBioscience, USA) for intracellular staining. Moreover, Isotype control was used anti-FOXP3 isotype (Rat IhG2 K, eFluor 660, eBioscience, USA). To determine $\mathrm{CD}^{+} \mathrm{CD} 25^{+} \mathrm{FOXP}^{+} \mathrm{T}_{\text {reg }}$ cells were analyzed by flow cytometry using BD FACSCalibur, BDBioscience (Figure 1).

\section{Cytokines determination}

The levels of IL-4, IL-13, IFN- $\gamma$, and IL-10 in the serum were detected using the BioLegend LEGENDplex ${ }^{\mathrm{mm}}$ commercial kit (Cat. No. 740723, Human cytokine panel (13-plex) with the filter plate, according to the manufacturers' instructions. Briefly, the stored serum was thawed and diluted by 2 -fold dilution with assay buffer before assay. These experiments are done in triplicate. The plasma was incubated with beads coat antibody detection in a rotator for 2 hours at room temperature. After that, each of the sample wells was added SA-PE reagent and incubated for 30 minutes, washed twice and kept in dark until determined by flow cytometry.

Table 1. Subcutaneous rush venom immunotherapy (VIT) protocol

\begin{tabular}{|c|c|c|c|c|c|}
\hline Day & $\begin{array}{c}\text { Injection } \\
\text { number }\end{array}$ & $\begin{array}{c}0.1 \\
\mathrm{mcg} / \mathrm{ml}\end{array}$ & $\begin{array}{c}1 \\
\mathrm{mcg} / \mathrm{ml}\end{array}$ & $\begin{array}{c}10 \\
\mathrm{mcg} / \mathrm{ml}\end{array}$ & $\begin{array}{c}100 \\
\mathrm{mcg} / \mathrm{ml}\end{array}$ \\
\hline \multirow[t]{6}{*}{ Day 1: Cumulative dose $2.25 \mathrm{mcg}$} & 1 & 0.1 & & & \\
\hline & 2 & 0.4 & & & \\
\hline & 3 & & 0.1 & & \\
\hline & 4 & & 0.5 & & \\
\hline & 5 & & 0.8 & & \\
\hline & 6 & & 1 & & \\
\hline \multirow[t]{5}{*}{ Day 2: Cumulative dose $64 \mathrm{mcg}$} & 7 & & & 0.2 & \\
\hline & 8 & & & 0.4 & \\
\hline & 9 & & & 0.8 & \\
\hline & 10 & & & & 0.2 \\
\hline & 11 & & & & 0.3 \\
\hline \multirow[t]{2}{*}{ Day 3: Cumulative dose $100 \mathrm{mcg}$} & 12 & & & & 0.4 \\
\hline & 13 & & & & 0.6 \\
\hline
\end{tabular}



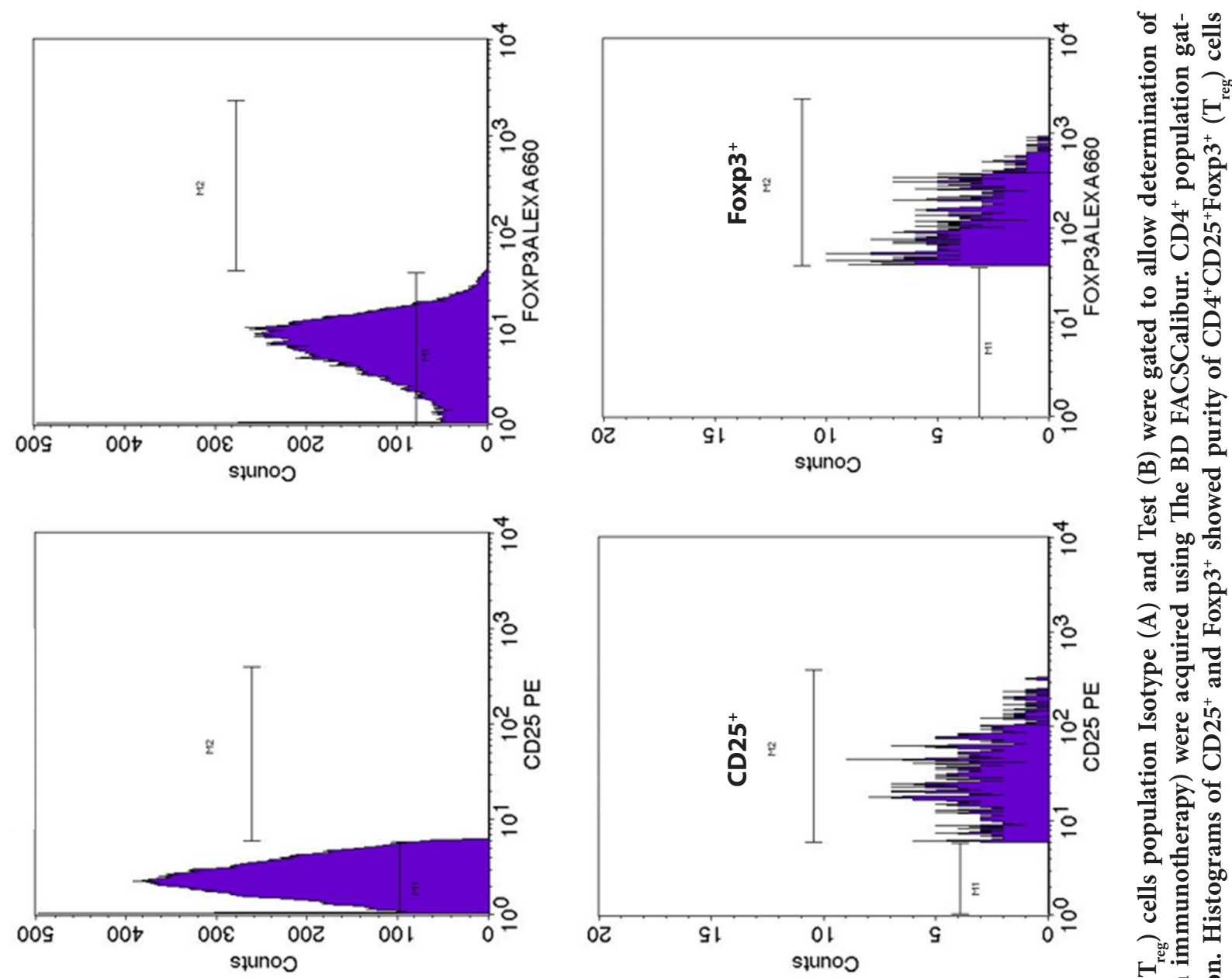

速旦

0. के

ह

¿

政

要

政

至능

:

oso

$\underbrace{ \pm} . \Xi$
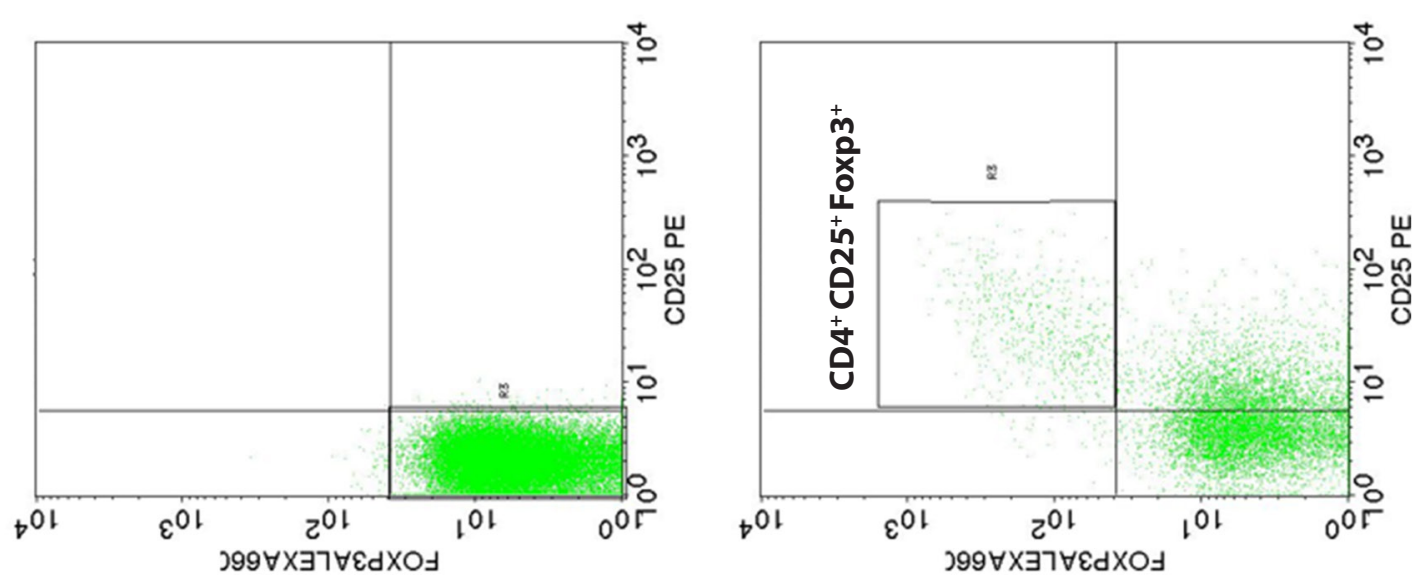

붕

초

要

可 ?

है

艎

กิ $\Xi$

它起+

ชิ

ڤั

원

窇
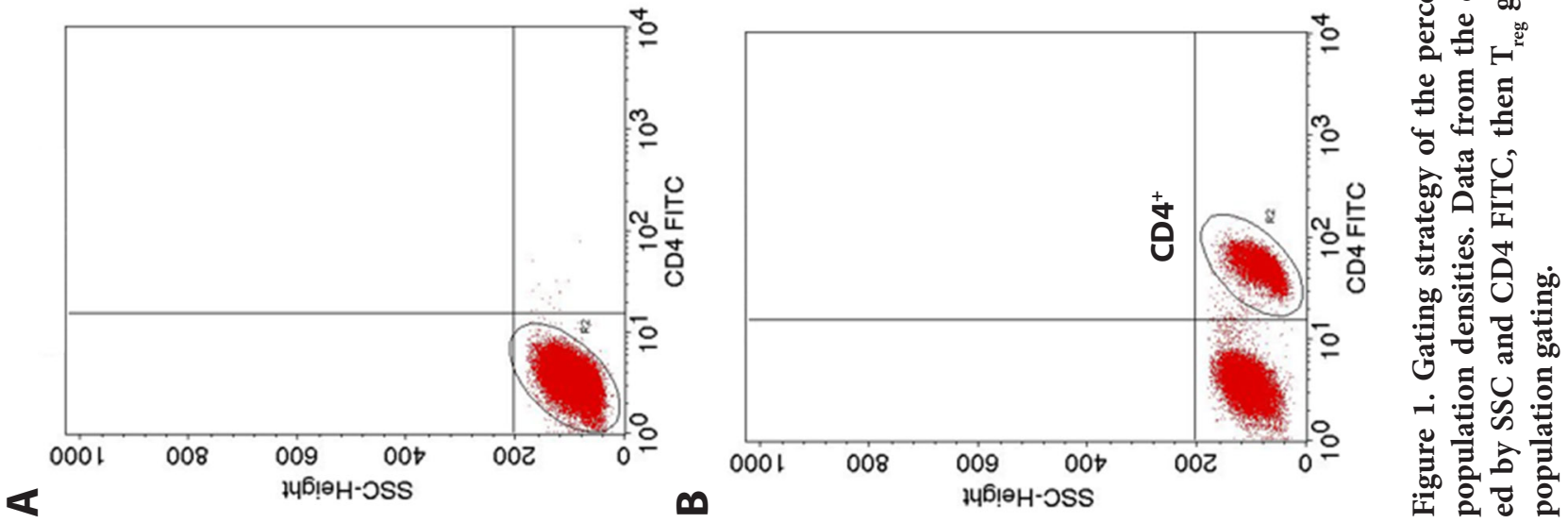


\section{Statistical analysis}

Statistical analysis was performed with the SigmaPlot V14 software. Data from flow cytometry and serum cytokine levels were analyzed using the repeated measure ANOVA. The data are presented as median and IQR for non-parametric data and mean \pm SD for parametric data.

\section{Results}

A total of 15 children (11 boys and 4 girls) aged 6-15 years (mean age, 10 years) were enrolled with the mean age of 9 years. Four children were allergic to bee and 11 children were allergic to Vespids. The median (IQR) of Hymenoptera sIgE was $8.70(2.98-49.80) \mathrm{kU} / \mathrm{L}$. There were no significant changes in Hymenoptera sIgE after 1 year of VIT (Figure 2A). The systemic reactions during rush VIT occurred in 3 cases who were on Vespid venoms rush VIT (Table 2). One child developed anaphylaxis required intramuscularly epinephrine injection at the dose of $40 \mathrm{mcg}$ of the Hymenoptera venom and 2 children developed urticaria required antihistamine treatment. All children responded well to the treatment and had no other systemic reactions from VIT. All enrolled children reached the maintenance dose of $100 \mathrm{mcg}$. No children had a systemic reaction to VIT during the MN phase.

A
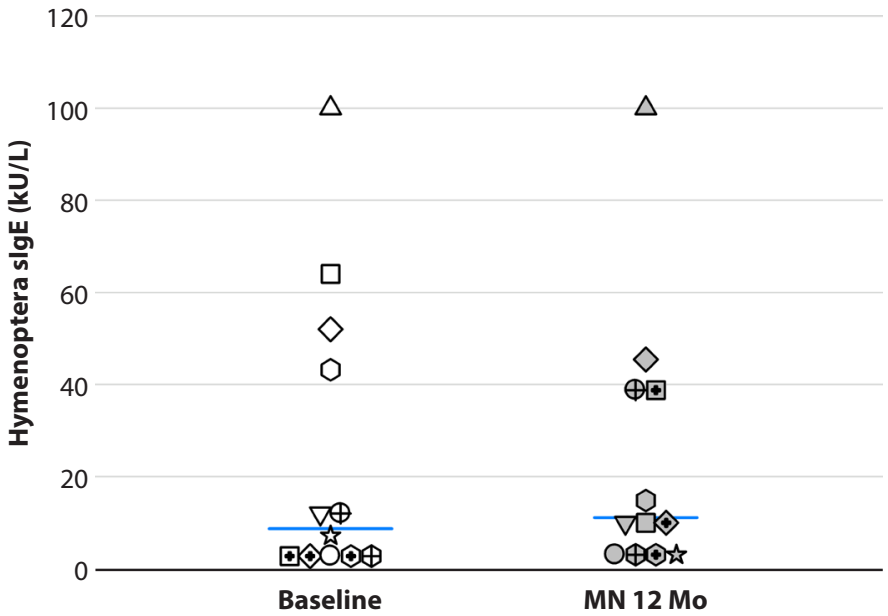

Dynamic changes of $\mathrm{CD}^{+} \mathrm{CD}^{+} 5^{+} \mathrm{FOXP3}^{+}$regulatory $\mathrm{T}\left(\mathrm{T}_{\text {reg }}\right)$ cells and cytokines during rush VIT

There was a trend to increase $\mathrm{T}_{\text {reg }}$ when achieving $\mathrm{MN}$ dose but it was failed to reach statistically significant. However, the percentage of $\mathrm{T}_{\text {reg }}$ in $\mathrm{CD} 4^{+}$cells was significantly increased at 6 and 12 months after $\mathrm{MN}$ when compared to those of the baseline and MN time points (Figure 2B). No correlations between $\operatorname{sgE}$ and the percentage of regulatory $\mathrm{T}$ cell at baseline and after 12 months of maintenance dose was demonstrated. There were no significant changes of the IFN- $\gamma$ in the serum after VIT at MN dose, 6 months after MN, and 12 months after MN when compared to the baseline levels (Figure 3A). However, there was a significant reduction of IL-4 in the serum at 12 months after $\mathrm{MN}$ when compared to the baseline levels (Figure 3B). The baseline serum of IL-10 was detected only in 5 out of 15 children. Interestingly, at 12 months after MN dose, IL-10 in the serum was able to be measured in 11 children, but this was failed to reach statically significant (Figure 4A). There were no significant changes in serum IL-13 after VIT treatment (Figure 4B).

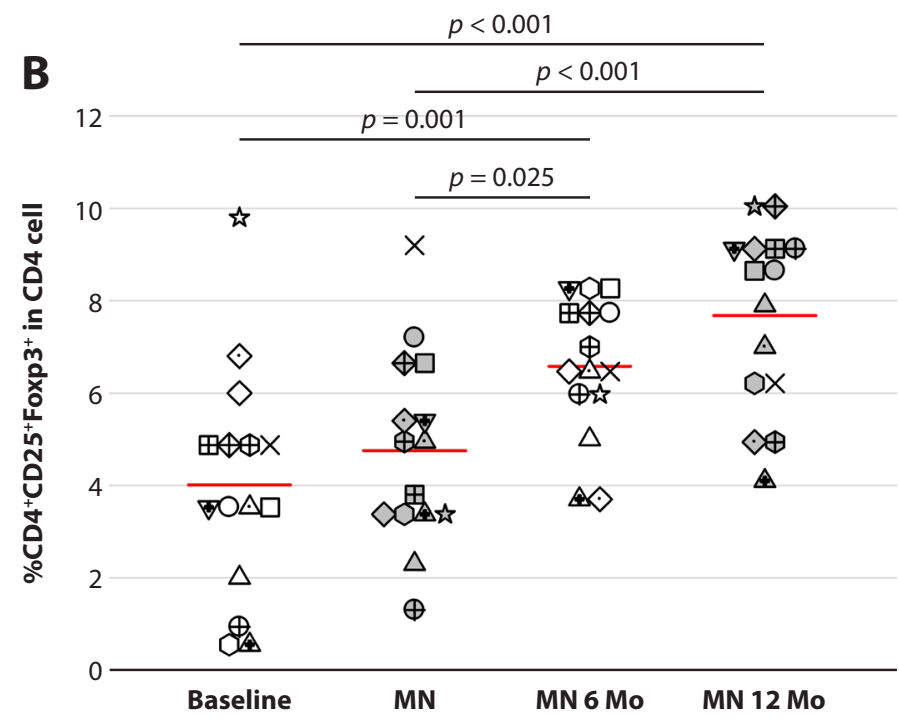

Figure 2. Dynamic changes of (A) serum specific IgE to Hymenoptera at baseline and 12 months after MN dose of VIT (MN 12 Mo) and (B) the percentage of $\mathrm{CD}^{+} \mathrm{CD}^{+} 5^{+} \mathrm{FOXP3}^{+}\left(\mathrm{T}_{\text {reg }}\right)$ in $\mathrm{CD}^{+}$cells at baseline, at maintenance (MN) dose, 6 months after MN dose (MN 6 Mo) and 12 months after MN dose (MN 12 Mo).Different symbols represent the data of each patient.

Table 2. Characteristic of patients who had systemic reactions during rush VIT

\begin{tabular}{ccccccc}
$\begin{array}{c}\text { Age } \\
\text { (years) }\end{array}$ & Sex & Allergen & $\begin{array}{c}\text { Dose with } \\
\text { reaction }\end{array}$ & Symptoms & $\begin{array}{c}\text { Systemic } \\
\text { Reaction } \\
\text { Grading* }\end{array}$ & Treatments \\
\hline 9 & Male & Vespids & $40 \mathrm{mcg}$ & Acute urticaria & Grade 1 & IV antihistamine \\
\hline 6 & Male & Vespids & $30 \mathrm{mcg}$ & Acute urticaria & Grade 1 & IV antihistamine \\
15 & Male & Vespids & $30 \mathrm{mcg}$ & $\begin{array}{c}\text { Angioedema } \\
\text { Decreased PEFR } \\
\text { Abdominal pain }\end{array}$ & Grade 2 & $\begin{array}{c}\text { Epinephrine IM } \\
\text { Antihistamine }\end{array}$
\end{tabular}

* The World Allergy Organization Subcutaneous Immunotherapy Systemic Reaction Grading System 
A

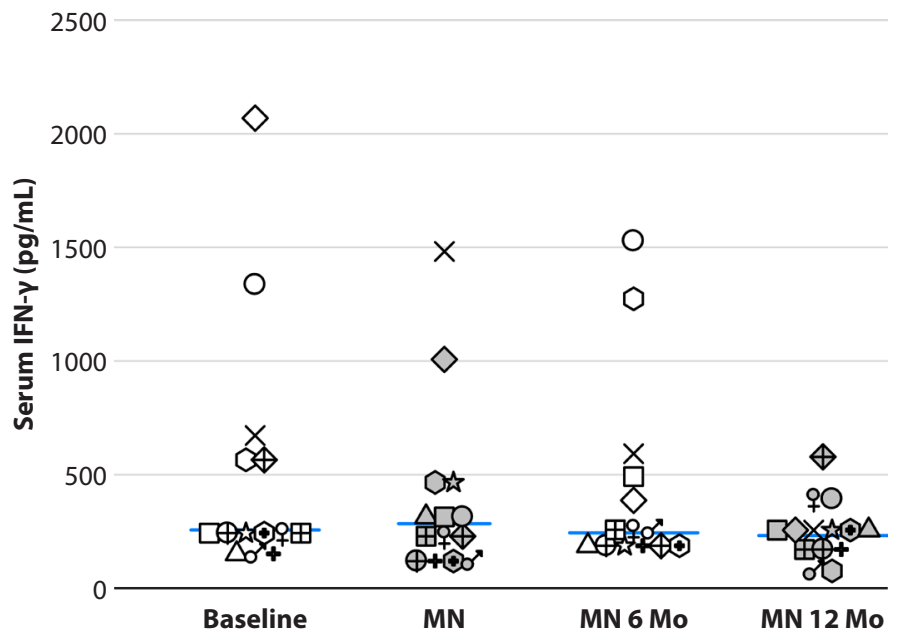

B

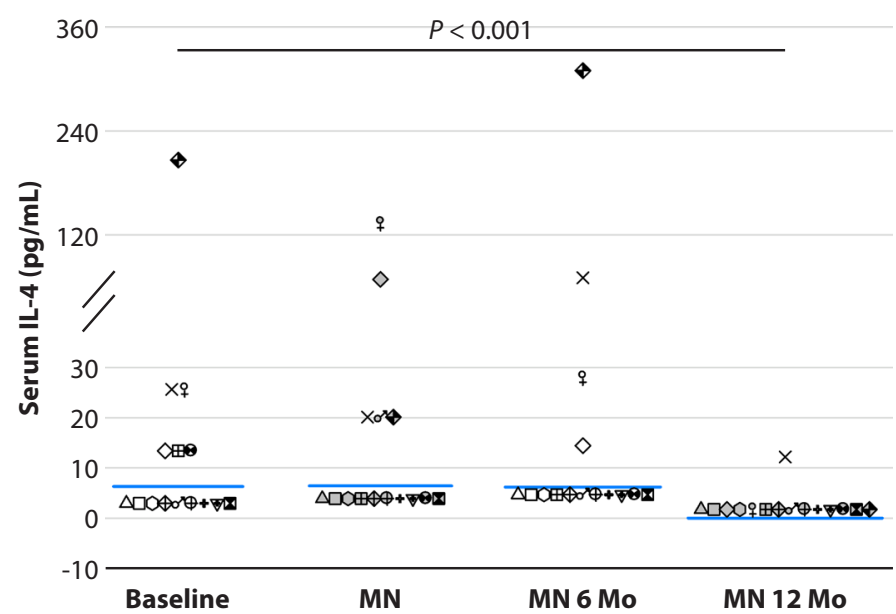

Figure 3. Dynamic changes of (A) serum IFN- $\gamma$ and (B) IL-4 at baseline, at maintenance (MN) dose, 6 months after MN dose (MN $6 \mathrm{Mo})$, and 12 months after MN dose (MN $12 \mathrm{Mo})$.

A

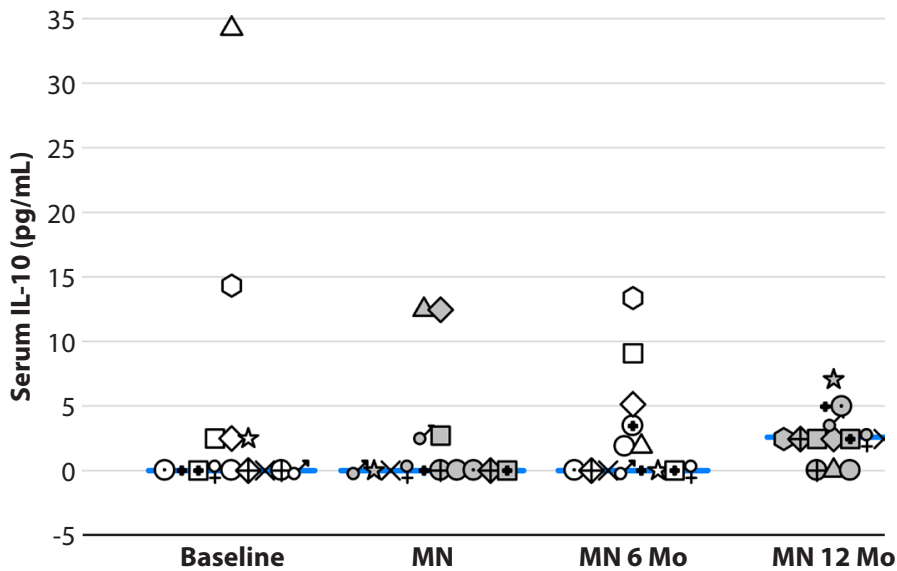

B

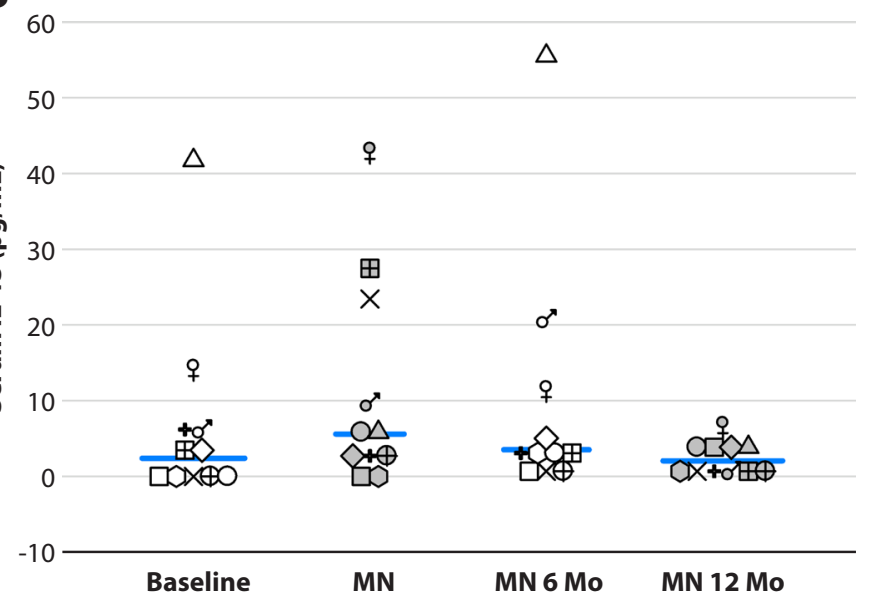

Figure 4. Dynamic changes of (A) serum IL-10 and (B) IL-13 at baseline, at maintenance (MN) dose, 6 months after MN dose (MN 6 Mo), and 12 months after MN dose (MN 12 Mo).

\section{Discussion}

In the current study, we have demonstrated that our 3 days rush VIT protocol was safe in children with Hymenoptera anaphylaxis. Only 1 child out of 15 children had a severe systemic reaction requiring IM epinephrine treatment. We have also have shown the trend to increase in the number of $\mathrm{CD}^{+} \mathrm{CD} 25^{+} \mathrm{FOXP} 3^{+} \mathrm{T}_{\text {reg }}$ after reaching the maintenance dose. $\mathrm{CD}^{+} \mathrm{CD} 25^{+} \mathrm{FOXP}^{+} \mathrm{T}_{\text {reg }}$ was significantly increased at 6 months after $\mathrm{MN}$ dose and it was sustained increased at 12 months. Additionally, the level of serum IL-4 decreased significantly after receiving the $\mathrm{MN}$ dose of VIT for 1 year.

The expansion of circulating $\mathrm{CD}^{+} \mathrm{CD} 25^{+} \mathrm{FOXP}^{+} \mathrm{T}_{\text {reg }} \mathrm{T}$ cells after rush VIT in the current study is line with the previous study in adult patients receiving rush VIT. ${ }^{3}$ Increased in the number of $\mathrm{CD}^{+} \mathrm{CD} 25^{+} \mathrm{FOXP} 3^{+} \mathrm{T}_{\text {reg }}$ cells after VIT was suggested to play a pivotal role for the development of allergen-specific immune tolerance. ${ }^{7}$ A study in children using $\mathrm{CD}^{+}{ }^{+} \mathrm{CD} 25^{\text {high }} \mathrm{CD}^{-} 9^{-}$as a marker for $\mathrm{T}_{\text {reg }}$ cells found no changes of $\mathrm{T}_{\text {reg }}$ cells after rush VIT. ${ }^{8}$ However, $\mathrm{CD} 4^{+} \mathrm{CD} 25^{+} \mathrm{FOXP}^{+}$ is a better marker for $\mathrm{T}_{\text {reg }}$ cells than $\mathrm{CD}^{+} \mathrm{CD}$ 25highCD69A recent study in beekeepers has also shown an increase in the number of $\mathrm{CD}^{+} \mathrm{CD} 25^{+} \mathrm{FOXP} 3^{+} \mathrm{T}_{\text {reg }}$ in those had no systemic reactions upon re-exposure to Bee stings. ${ }^{9}$

We found the significantly decreased in the level of serum IL-4 at 1 year after MN of VIT, but there were no changes in serum IFN- $\gamma$. A shifting in Th2 to Th1 response after VIT as demonstrated by an increase in IFN- $\gamma$ and decrease in IL-4 in whole blood cell-cultured supernatant. ${ }^{10}$ The reason that we did not found the changes in the serum IFN- $\gamma$ after VIT may explain from the difference in the method of detecting the cytokine. The changes in IFN- $\gamma$ after VIT may be modest to be detected in the serum but possible to be detected in whole blood cell-cultured supernatant. We also found a trend toward an increase in serum IL-10 after VIT. Increased in the level of IL-10 was shown in the development of clinical and immunological tolerance during VIT and also in beekeepers receiving multiple bee stings. ${ }^{11,12}$ The decreased in IL- 4 and 
increased in the percentage of $\mathrm{T}_{\text {reg }}$ in the present study is in line with the previous studies in adults receiving VIT. This can be implied that VIT is equally effective in adults and children.

The systemic reaction during the build-up phase in rush VIT was shown to be comparable to conventional VIT both in adults and in children. ${ }^{13-15}$ However, the time to MN dose which provides both immunological and clinical allergen tolerance are significantly shorter in rush VIT. Our 3-days rush VIT protocol with a total of 13 injections was shown to provide the immunological tolerance from increased the number of $\mathrm{CD}^{+} \mathrm{CD} 25^{+} \mathrm{FOXP} 3^{+} \mathrm{T}_{\text {reg }} \mathrm{T}$ cells when reaching the $\mathrm{MN}$ dose. However, we did not perform the insect sting challenge to confirm for the clinical tolerance and all of our enrolled children did not expose to the culprit insect during the study period. Of 15 enrolled children, 3 (20\%) children developed systemic reactions during VIT. The incidence of systemic reaction in our rush VIT protocol is in line with other rush VIT protocols which ranged from 19-30\%. ${ }^{13-15}$ The limitation of the present study is that we could not enroll more children due to the worldwide shortage for the supply of venom for immunotherapy.

In summary, the present study demonstrates the safety and evidence of immunological tolerance of 3 days rush VIT in children with venom anaphylaxis. This 3 days rush VIT could be a treatment for children with Hymenoptera anaphylaxis who require rapid protection from insect stings.

\section{Acknowledgments}

This study was financially supported by research funds from the Faculty of Medicine Ramathibodi Hospital, Mahidol University, Thailand.

\section{Disclosure of conflicts of interest}

None of the authors have any conflicts of interest to disclose

\section{References}

1. Koterba AP, Greenberger PA. Chapter 4: Stinging insect allergy and venom immunotherapy. Allergy Asthma Proc. 2012;33 Suppl 1:12-4.

2. Sturm GJ, Varga EM, Roberts G, Mosbech H, Bilo MB, Akdis CA, et al EAACI guidelines on allergen immunotherapy: Hymenoptera venom allergy. Allergy. 2018;73:744-64

3. Pereira-Santos MC, Baptista AP, Melo A, Alves RR, Soares RS, Pedro E, et al. Expansion of circulating Foxp3+)D25bright CD4+ T cells during specific venom immunotherapy. Clin Exp Allergy. 2008;38:291-7.

4. Bellinghausen I, Metz G, Enk AH, Christmann S, Knop J, Saloga J. Insect venom immunotherapy induces interleukin-10 production and a Th2-to-Th1 shift, and changes surface marker expression in venom-allergic subjects. Eur J Immunol. 1997;27:1131-9.

5. Jutel M, Pichler WJ, Skrbic D, Urwyler A, Dahinden C, Muller UR. Bee venom immunotherapy results in decrease of IL- 4 and IL-5 and increase of IFN-gamma secretion in specific allergen-stimulated T cell cultures. J Immunol. 1995;154:4187-94.

6. Cox L, Larenas-Linnemann D, Lockey RF, Passalacqua G. Speaking the same language: The World Allergy Organization Subcutaneous Immunotherapy Systemic Reaction Grading System. J Allergy Clin Immunol. 2010;125:569-74, 74 e1-74 e7.

7. Sahiner UM, Durham SR. Hymenoptera Venom Allergy: How Does Venom Immunotherapy Prevent Anaphylaxis From Bee and Wasp Stings? Front Immunol. 2019;10:1959.

8. Ajduk J, Turkalj M, Gagro A. Regulatory T cells in children undergoing rush venom immunotherapy. Allergy Asthma Proc. 2012;33:525-30.

9. Santos MCP, Serra-Caetano A, Pedro E, Melo A, Caramalho I, Barbosa MP, et al. Expansion of FOXP3(+) regulatory CD4 T cells upon exposure to hymenoptera venom during the beekeeping season. Allergy. 2019;74: 1182-4.

10. Mamessier E, Birnbaum J, Dupuy P, Vervloet D, Magnan A. Ultra-rush venom immunotherapy induces differential $\mathrm{T}$ cell activation and regulatory patterns according to the severity of allergy. Clin Exp Allergy. 2006;36: 704-13.

11. Akdis CA, Blesken T, Akdis M, Wuthrich B, Blaser K. Role of interleukin 10 in specific immunotherapy. J Clin Invest. 1998;102:98-106.

12. Bussmann C, Xia J, Allam JP, Maintz L, Bieber T, Novak N. Early markers for protective mechanisms during rush venom immunotherapy. Allergy. 2010;65:1558-65.

13. Confino-Cohen R, Rosman Y, Goldberg A. Rush Venom Immunotherapy in Children. J Allergy Clin Immunol Pract. 2017;5:799-803.

14. Goldberg A, Yogev A, Confino-Cohen R. Three days rush venom immunotherapy in bee allergy: safe, inexpensive and instantaneously effective. Int Arch Allergy Immunol. 2011;156:90-8.

15. Stoevesandt J, Hosp C, Kerstan A, Trautmann A. Safety of 100 microg venom immunotherapy rush protocols in children compared to adults. Allergy Asthma Clin Immunol. 2017;13:32. 